\title{
Protein Tertiary Structure Modeling Driven by Deep Learning and Contact Distance Prediction in CASP13
}

\author{
Jianlin Cheng \\ Department of Electrical Engineering and Computer Science \\ University of Missouri \\ Columbia, MO 65211, USA \\ chengji@missouri.edu
}

\begin{abstract}
$\mathrm{Ab}$ initio prediction of protein structure from sequence is one of the most challenging and important problems in bioinformatics and computational biology. After a long period of stagnancy, ab initio protein structure prediction is undergoing a revolution driven by inter-residue contact distance prediction empowered by deep learning. In this talk, I will present the deep learning and contact distance prediction methods of our MULTICOM protein structure prediction system that was ranked among the top three best methods in the $13^{\text {th }}$ community-wide Critical Assessment of Techniques for Protein Structure Prediction (CASP13) in 2018 [1]. MULTICOM was able to correctly fold structures of numerous hard protein targets from scratch in CASP13, which was an unprecedented progress. The success clearly demonstrates that contact distance prediction is the key direction to tackle the protein structure prediction challenge and deep learning is the key technology to solve it. However, to completely solve the problem, more advanced deep learning methods are needed to accurately predict inter-residue distances when few homologous sequences are available to calculate residue-residue co-evolution scores, fold proteins from noisy inter-residue distances, and rank the structural models of hard protein targets.
\end{abstract}

\section{CCS CONCEPTS}

- deep learning • bioinformatics • machine learning

\section{KEYWORDS}

Deep convolutional neural network, deep learning, protein structure prediction, protein contact prediction, protein distance prediction

\section{ACM Reference format:}

Jianlin Cheng. 2019. Protein tertiary structure modeling driven by deep learning and contact distance prediction in CASP13. In Proceedings of the $10^{\text {th }}$ ACM Conference on Bioinformatics, Computational Biology, and Health Informatics (ACM BCB'19), Spet. 7-10, Niagara Falls, NY, USA. ACM, New York, NY, USA. 1 page. https://doi.org/10.1145/1234567.

\section{ACKNOWLEDGMENTS}

The work is supported by the National Natural Science Foundation (NSF) under two grants (Grant No.: DBI1759934 and IIS1763246) and an NIH grant (Grant No. R01GM093123).

\section{REFERENCE}

[1] Jie Hou, Tianqi Wu, Renzhi Cao, Jianlin Cheng. 2019. Protein tertiary structure modeling driven by deep learning and contact distance prediction in CASP13. Protein. In press. https://doi.org/10.1002/prot.25697
Permission to make digital or hard copies of part or all of this work for personal or classroom use is granted without fee provided that copies are not made or distributed for profit or commercial advantage and that copies bear this notice and the full citation on the first page. Copyrights for third-party components of this work must be honored. For all other uses, contact the Owner/Author. ACM-BCB '19, September 7-10, 2019, Niagara Falls, NY, USA.

(C) 2019 Copyright is held by the owner/author(s).

ACM ISBN 978-1-4503-6666-3/19/09.

DOI: https://doi.org/10.1145/3307339.3342622 